\title{
Mobile Devices and Lifelong Learning: The Students' Perspective
}

\section{Prof. Susan L. Miertschin, University of Houston (CoT)}

Susan L. Miertschin, M.Ed., M.S.I.S., is an Associate Professor teaching in the Computer Information Systems program at University of Houston. Her teaching interests are in the areas of (1) information systems applications development and the complementary nature of back-end developer and front-end developer skill sets and (2) managing IT services. Her research interests are program and student assessment, the impact of instructional technology on student learning, and the improvement of e-learning environments and experiences.

\section{Dr. Barbara Louise Stewart, University of Houston}

Barbara L. Stewart is a Professor of Retailing and Consumer Science at the University of Houston. Her teaching and research interests are in the application of strategies to improve student learning and life enhancement in online courses. She has served as an academic administrator and in leadership positions for numerous professional organizations.

\section{Dr. Carole E. Goodson, University of Houston (CoT)}

Carole Goodson is a Professor of Technology at the University of Houston. As an active member of ASEE, she is a member of the Academy of Fellows, a past Editor of the Journal of Engineering Technology, a past Chair of PIC IV and the ERM Division, and a past Chair of the Gulf Southwest Section of ASEE. 


\section{Mobile Devices and Lifelong Learning: The Students' Perspective}

\section{Introduction}

Alvin Toffler, writer and former associate editor of Fortune magazine has often been quoted as saying that, "The illiterate of the 21 st century will not be those who cannot read and write, but those who cannot learn, unlearn, and relearn". ${ }^{1}$ With rapid advances in information and communication technologies (ICTs) that include devices becoming more portable, more intuitive, and not particularly costly, the process of pursuing knowledge for a lifetime has become more impelling. With advanced technical tools readily available, anyone with access has the opportunity to seek, renew, rekindle and thus, grow.

Although lifelong learning has become a particularly popular concept in the last several years, it is as old as human history. ${ }^{2}$ Lifelong learning typically refers to a formal or informal process characterized as open-ended, voluntary, and self-motivated with the aim of improving an individual's knowledge base. Both personal and professional reasons can motivate learning activity. Developing lifelong learning habits and skills in students has long been the aspiration of educators, and, more recently; it has become a requirement for program credibility. For example, an ABET student outcome requirement for engineering programs and one for applied science programs specifies that students have "recognition of the need for, and an ability to engage in life-long learning" 3,4 For engineering technology programs a similar ABET student outcome requirement is for students to have "an understanding of the need for and an ability to engage in self-directed continuing professional development". 5 For computing programs, the corresponding ABET student outcome requirement is for students to have "recognition of the need for and an ability to engage in continuing professional development". 6 Thus, all program categories served by ABET address the need for students to continue learning, especially in their profession, after they graduate.

Since the 1960s, the application of computers to education has evolved along with technology and, progressively, computers have been used to provide information, instruction, tutoring, testing, and more for students. With the advent of the World Wide Web in the 1990s and the subsequent development of mobile technologies in the twenty-first century, the use of computerbased mobile devices to provide learning experiences beyond the classroom has expanded. Sharples reported that mobile ICT supports lifelong learning in a number of ways. ${ }^{7,8}$ Mobile hardware and software together with the infrastructure of the Internet provide a platform for learning and teaching that is highly portable and, thus, available whenever and wherever the user needs to learn. In addition, the variety of mobile hardware and software makes mobile learning adaptable to the learner's abilities and knowledge base. Further, mobile ICT enables communication with experts and peers, which is another element of lifelong learning. Mobile devices offer convenience for learning that is available throughout a long period of time, enabling the learner's personal accumulation of resources and knowledge. Use of the technologies is intuitive for most, which enables broader use, even by people with no previous experience with the technology.

If the intent of educators is to help students plan and realize learning goals for a lifetime, then it is important to understand how students perceive the lifelong learning process in the world of 
abundant information, readily accessible and portable through technology, both mobile and fixed. The intent of the current study was to explore the application of mobile devices to lifelong learning, particularly as students use it and perceive its utility in this context. A survey directed at these concepts was completed by 256 students enrolled in eight university courses in the spring of 2015. Using the results of the survey and related literature, the current study explored and addressed the following questions.

- What mobile devices are commonly utilized by students to support learning?

- How much do students use mobile devices for learning, especially compared to their use of laptops and desktops?

- How do students perceive that they can use mobile devices to continue learning?

\section{Lifelong Learning}

\section{Lifelong Learning: Historical Background}

Much consideration, both in the U.S. and internationally, has been given to lifelong learning as evidenced by thousands of published papers and journals devoted either entirely or in part to the topic, organizations focused on promotion of lifelong learning, and institutions and agencies which sponsor centers in support of it. ${ }^{2}$ Reasons for emphasis on lifelong learning include a) sustaining lifelong learning processes is directly related to the living standards of citizens and their quality of life, ${ }^{9}$ b) lifelong learning is a means of providing people with the knowledge and skills needed to succeed in a rapidly changing world, ${ }^{7} \mathrm{c}$ ) there is an explosion of ICT which enables knowledge to be produced at a rapid and an ever-increasing rate, ${ }^{2}$ and d) complex technologies arise that quickly change life and workplace demands, and, hence, call for workers and individuals who can adapt to change. ${ }^{2}$

While recently a topic of extensive review, lifelong learning is a concept deeply rooted in human history. Ancient Greeks, such as Plato and Aristotle described learning as a process over a lifetime involving the development of dispositions and capabilities which enable individuals toward continuous scholarship. From there, a long line of educators and theorists considered theses seated in the idea that people can be self-motivated and empowered toward a lifetime of continuous learning. ${ }^{2}$ Henschke cited educational examples from the Bible and from ancient teachers such as Confucius, Socrates, Quintilian, Cicero, and the Hebrew prophets, that expressed the concept that learning was to be lifelong. ${ }^{10}$

The value of lifelong learning, important to the ancients, was outlined more recently by Bosco when he proposed three rationales. ${ }^{2}$ First, economics is a driving rationale for formal as well as informal lifelong learning, because issues of workforce requirements and global competitiveness spur the need for learning. Second, learning enriches human life and enables individuals to enjoy the richness of human culture, building lifelong passions for intellectual and cultural growth. Third, lifelong learning is required to sustain life on earth because the complexity of technologically enhanced human existence has created a multitude of equally complex and serious problems. Continuous learning is needed to raise both the individual and collective levels of intelligence and understanding of humankind so that Man will be better prepared to protect and preserve life. 
While lifelong learning has long been central to the needs of societies and recognized as such, it has also been broadly unattainable with no easy ways to disseminate information, much less consistent and cohesive bodies of knowledge, to the masses. However, with rapid development and advancement of modern ICTs, a prediction Sharples made in 2002 is being fulfilled. He stated: "The hardware, software and communications technology will soon be available and affordable to allow people to learn anytime, anywhere and to share knowledge with colleagues and teachers. It offers the opportunity for children and adults to manage their own knowledge and learning across a lifetime of educational needs and experiences". ${ }^{8}$ Of future opportunities Bosco wrote that the prevalence and potency of resources for lifelong learning will continue to expand as developers of hardware and applications make continued progress. ${ }^{2}$ Thus, ICT is currently poised to further enable dramatic advances.

\section{Lifelong Learning: Toward a Definition}

While Sharples stated in 2000 that no accepted definition of lifelong learning exists, ${ }^{7}$ numerous authors since 2000 have addressed the task of defining or describing lifelong learning. Bosco expressed concern regarding a popular view that bonded education with schooling, since, in his view, education was a broader concept that encompassed all types of learning as opposed to just the learning acquired through formal schooling. He proposed that each moment of a person's life can be considered a moment of learning. Hence, his educational orientation focused less on degrees, diplomas, and certificates and more on capabilities and competencies. ${ }^{2}$ Sharples viewed as a basic premise of lifelong learning, that it is not feasible to equip learners at school or university with all they need to prosper throughout their lifetimes since people need to continually enhance their knowledge and skills. ${ }^{7,8}$ Bentley earlier expressed strongly the need to empower people across a variety of contexts to manage their own learning throughout life. ${ }^{11}$

The view that lifelong learning is embedded throughout the processes and stages of life was expressed by Bosco when he explained that if lifelong learning is defined as the acquisition of information and/or skills, then it is a natural human process from birth until death. ${ }^{2}$ Nordin, Embi, and Yunus similarly likened lifelong learning to seeking knowledge from the cradle to death. ${ }^{12}$ Laal summarized the notion with, "Lifelong learning literally means that learning should take place at all stages of [the] life cycle, from the cradle to the grave, and ... it should be lifewide, that is embedded in all life contexts from the school to the workplace, the home and the community". ${ }^{13}$ As described by Sharples, lifelong learning represents an extended and holistic process of developing skills and understanding where the abilities and tools for learning gained from various life stages (e.g., childhood) and various sources (e.g., schooling) provide a context and resource for learning and performing in later life. ${ }^{8}$ Lifelong learning capability is seen when an individual or group reflects on the current situation and resolves to address a problem, to share an idea, or to do research and further study to gain a better understanding of the situation. Thus, lifelong learning happens serendipitously in the workplace, at home, and at play, as part of daily living.

Some authors have written on the role of technology in lifelong learning. Idrus and Atan suggested that life-wide learning hinges on technology mediated communication (achieved with ICT). ${ }^{14}$ Similarly, the use of technology to provide flexible learning frameworks, often preferred by adults, was advocated by Nordin, et al. ${ }^{12}$ The power offered by technology was evident in 
Laal's statement that "in lifelong learning the role of information and communication technology is one of empowerment, enhancement of creativity, and support". ${ }^{13}$

Henschke offered a viable definition of lifelong learning that encompassed much of what was said elsewhere. He wrote, "Lifelong Learning is a master concept or [andragogical] principle regarded as the continuous and never complete development, changes, and adaptation in human consciousness including learning that occurs partly through deliberate action of Non-Formal, Informal, Formal educational systems, but even more as a result of the business of living; and, may be intentional or unintentional that includes acquiring greater understanding of other people and the world at large, based on six pillars of learning: learning to know ..., learning to do ..., learning to live together ...; learning to be ...; learning to change ...; learning for sustainable development". 10

\section{Mobile Learning}

\section{Mobile Learning: Historical Background}

According to Hargreaves, a knowledge society is a learning society with responsibility to provide avenues for its people to seek knowledge. ${ }^{15}$ With the development of ICT over time, knowledge acquisition is certainly not restricted to classrooms. In fact, the technological evolution which spawned broad access to mobile devices has brought significant growth in and encouraged the extension of educational processes towards lifelong learning through these devices. ${ }^{9}$ This realization is consistent with the perspective that education, now including mobile learning, is formed by the technology of its era. In the era of mass print literacy, the textbook was the primary medium of instruction with the goal of transmission of information. The computer era brought a reconceptualization that knowledge is constructed through information processing, modeling, and interaction. Now, in the era of mobile technology, education is conceived as conversation in context, enabled by continual interaction through personal, mobile technology. ${ }^{16}$

\section{Mobile Learning: Toward a Definition}

Winters stated, "Mobile learning, as a concept, is currently ill-defined". ${ }^{17}$ Attempting to clarify, Taylor, at the same conference, led a discussion of whether mobile learning signified learning mediated by mobile devices or the mobility of learners regardless of their devices or the mobility of resources that can be accessed from anywhere. ${ }^{18}$ All of these conceptualizations focus on enabled variation in location of learners and/or learning resources, but there is also an aspect of time in the concept of mobility.

Technology has created new conditions for learning, and place and mobility have been identified as primary factors of mobile learning with the aspect of time being mentioned explicitly by some. For example, Walker viewed mobile learning as part of a greater whole in which learning tools, activities, contexts, and people are distributed over both time and place. Mobility, for Walker, was about a learning society on the move. ${ }^{19}$ It is the learner that is mobile, rather than the technology according to Sharples, Taylor and Vavoula. ${ }^{16}$ Nordin, et al., described lifelong learning as learning that can happen anytime and anywhere according to the needs of the 
individual. ${ }^{12}$ This conceptualization encompasses both place and time, but does not explicitly mention the aspect of mobility, though it may be implied.

\section{Mobile Learning: Criteria \& Frameworks}

Because the discipline and practice of mobile learning is immature, and due to the lack of a clear definition of mobile learning, multiple frameworks and criteria for mobile learning have been proposed and discussed. In 2005, Sharples, et al., summarized the collective wisdom of the participants of a conference held on mobile learning. Attempting to offer an initial framework for theorizing about mobile learning, they delineated characteristics that distinguish mobile learning from other types of learning activity ${ }^{16}$. The characteristics identified included: a) mobile learning assumes learners are continually on the move, learning across space, taking ideas and resources gained in one location and applying or developing them in another; b) mobile learning occurs across time in that learners revisit knowledge gained earlier in different contexts; ideas and strategies gained in early years provide frameworks for a lifetime of learning; c) mobile learners move from topic to topic, managing a range of personal learning projects rather than a set, formal curriculum; and d) mobile learners move in and out of engagement with technology. Sharples, et al., as a further step in postulating a theory of mobile learning, set forth characteristics that distinguish mobile learning when compared to other types of learning and make it worth special consideration. They acknowledged that considerable learning occurs outside classrooms. They documented contemporary accounts of ubiquitous use of personal and shared technologies that enable successful learning. Conclusions that they reached included: a) it is the learner rather than the technology that is mobile; b) learning is interwoven with other activities as part of everyday life; c) learning can generate as well as satisfy goals; d) the control and management of learning can be distributed; e) context is constructed by learners through interaction; f) mobile learning can both complement and conflict with formal education; and g) mobile learning raises deep ethical issues of privacy and ownership. In sum, they said, “... the distinctive aspects of mobile learning are its mobility, the informally arranged and distributed participants, and the interaction between learning and profitable technology". ${ }^{16}$

In 2006, Winters offered as criteria for classifying learning as mobile learning the following: a) is technology centric, b) has a relationship to e-learning, c) augments formal education, and d) is learner centered. ${ }^{17}$ Similarly, Jones, et al., offered six reasons why mobile learning is motivating. These were a) control over goals, b) ownership, c) fun, d) communication, e) learning-in-context, and f) continuity between contexts. ${ }^{20}$ By 2010, Nordin, et al., were prepared to present both a list of crucial factors for the development of a theory of mobile learning and a framework for mobile learning. Their crucial factors included: a) an underlying assumption that learners are on the move, b) understanding that learning takes place outside the classroom, c) belief that mobile learning must be learner centered, knowledge centered, assessment centered, and community centered; and d) consideration of the use of ubiquitous technology and how learning responds to that technology. Based on these factors, their framework included theories of learning, the generic mobile environment, the mobile learning context, and the learning experience and objectives. $^{12}$

\section{Technology/Devices: Historical Background}


Technology and technological devices are stimulating increased access to mobile and lifelong learning today. As the development of technologies for learning progressed over time, there was convergence of preconditions for lifelong learning with new technologies. Sharples illustrated the match between emergent ICTs and lifelong learning. He outlined necessary characteristics for lifelong learning as individualized, learner centered, situated, collaborative, ubiquitous, and lifelong. He outlined requirements for supporting technologies as needing to be personal, user centered, mobile, networked, ubiquitous, and durable. ${ }^{7}$ The progression of technology development with greater understanding of what constitutes lifelong learning enabled Kalz to observe that now "more personal technologies are used for lifelong learning to support selforganized learning". ${ }^{21}$

\section{Technology/Devices: Definitions}

Current analyses of technology and devices for mobile learning focus on their roles in support, communication, and mediation. The spectrum of technology and devices for mobile learning includes mobile devices (tablets and smartphones), portable devices (laptops), and non-mobile devices (desktops), plus infrastructure such as networks, communication protocols, and programming libraries that make application development faster while producing more reliable applications. While each technology could be examined for its role in mobile learning, much of the literature considers the whole of these technologies as they collectively support learning. Nordin, et al., succinctly captured their role in support as "... technologies can be seen as the supporting factor of learning". ${ }^{12}$ Similarly, Sharples, et al., described technology as a tool that serves the purpose of inquiry. ${ }^{16}$ Ion and Bentley captured the role of technology in communication with, “... mobile devices provide support especially for fast communication. Mobile devices have the main role of providing support for achieving synchronous and asynchronous communication between users". ${ }^{9}$ Two basic functionalities of mobile devices are rapid communication and information transmission. These, in everyday life, encourage voluntary or organized involvement in educational activities. In the same manner, Sharples, et al., proposed that computers and mobile phones, specifically, work as interactive agents in the process of coming to know; they create a human-technology system to communicate, to aid recall and reflection, and to mediate agreements between learners. ${ }^{16}$ The mediation function is the third role researchers have identified. Winters expressed that "learning is mediated through mobile technologies" and that "mobile learning applications are best viewed as mediating tools in the learning process" ${ }^{17}$ Finally, Sharples, et al., viewed technologies as " $\ldots$ instruments for productive inquiry as part of a process of learning through exploration of the world and negotiation of meaning" ${ }^{16}$ thus recognizing that learning is mediated by technology.

\section{Technology/Devices: Criteria and Frameworks}

Sharples, in his work to develop a framework for use of mobile ICT for lifelong learning, first identified five roles for technology including roles as substitute teacher, computer-based assistant and mentor, computer-based tools and resources, communications aid, and computer-based learning environment. He further suggested that the various roles for technology to support lifelong learning are not mutually exclusive. That is, technology could serve simultaneously as tutor, guide, assistant, communications aid, and learning environment in support of lifelong learning. Based on these roles, he then described critical requirements for the tools used for 
lifelong learning. The tools for lifelong learning must be highly portable, individual, unobtrusive, available anywhere, adaptable, persistent, useful, and intuitive. ${ }^{7}$

\section{Current Study}

Motivated by a desire to understand students' use of mobile technologies for learning and students' perception of how useful mobile technologies are for lifelong learning, as initial steps to exploring the applications of mobile devices for lifelong learning, the researchers created and disseminated a survey directed at these concepts. The survey was completed by students enrolled in eight university courses in the spring of 2015. Included were courses in computer information systems, research methods, merchandising systems, statistics, and supervision. Altogether, twohundred and fifty six (256) students at the University of Houston were surveyed.

The research aimed to obtain a clearer understanding of answers to the following questions.

- What mobile devices are commonly utilized by students to support learning?

- How much do students use mobile devices for learning, especially compared to their use of laptops and desktops?

- How do students perceive that they can use mobile devices to continue learning?

\section{Study Procedures}

Two hundred fifty-six (256) students enrolled in five courses that varied in subject, level, and delivery mode elected to complete the study survey (see Table 1). All courses included an online course interface delivered though a common course management system, Blackboard ${ }^{\circledR}$ Learn. Online courses used the Blackboard ${ }^{\circledR}$ Learn interface as the exclusive delivery system for the course, while face-to-face and hybrid courses used the interface to supplement traditional inperson course delivery and management practices.

Table 1 Courses Used for Survey Administration

\begin{tabular}{|l|l|l|}
\hline \multicolumn{1}{|c|}{ Course } & \multicolumn{1}{c|}{ Level } & \multicolumn{1}{c|}{ Format } \\
\hline Information Systems Applications (2334) & Lower division (sophomore) & Face-to-Face \\
\hline Integrated Information Systems (3355) & Upper division (junior) & Face-to-Face \\
\hline Visual Merchandising (3304) & Upper division (junior) & Online \\
\hline Database Admin. \& Implementation (4338) & Upper division (senior) & Face-to-Face \\
\hline Research Concepts in HDCS (4300) & Upper division (senior) & Online \\
\hline Project Management \& Practice (4375) & Upper division (senior) & Face-to-Face \\
\hline Data Analysis & Graduate & Online/Hybrid \\
\hline
\end{tabular}

While the courses through which students completed the survey included face-to-face, hybrid, and online formats, the survey questions were directed at the students' overall experience with mobile technologies and learning, as opposed to their experience in the particular course or course format in which they were surveyed. Experience with online learning was important to the researchers as mobile learning is enabled by online technologies and because the researchers have an established interest in online learning environments. More relevant than the course in 
which the student was enrolled, was the amount of personal experience the students had with using mobile technologies in courses of all formats. The survey was implemented through the assessment module of Blackboard Learn. Students were assured that completion of the survey was voluntary and that all responses would be anonymous to the instructor and the researchers and would remain anonymous upon publication of any results. The students were instructed to answer the questions with respect to their college learning experiences, in general, and not with respect to the specific course that delivered the survey. Student responses were downloaded for analysis; each response record was identified by a number assigned by the learning management system used to deliver the survey.

The survey instrument consisted of 44 items. The first section addressed student demographic characteristics including: 1) student classification (freshman, sophomore, etc.), 2) number of online courses completed, 3) enrollment status (mostly full-time or mostly part-time), 4) age, 5) estimated overall GPA, 6) employment status, 7) gender, 8) major, and 9) course format.

Following the demographic section the survey addressed the following areas:

- type of devices that the student used (desktop, laptop, tablet, and/or smartphone) and the nature of that use (academic, non-academic, both, neither)

- preferences for technology features potentially used in classes

- use of mobile devices for learning

- issues related to lifelong learning and the relationship of mobile devices to lifelong learning

Finally, open-ended questions were presented in the survey to further explore contributions that the institution and individual instructors can make to the lifelong learning process, specifically to what they can do with technology. The open-ended question responses are being analyzed separately to be reported in another paper.

Student responses to the survey items described were tabulated; tables, graphs, and descriptive measures were used to analyze the data.

\section{Study Results}

\section{Demographics}

Eighty-eight percent of the participating students were classified as at least juniors, and thus, were experienced students. The students were also experienced with online courses; $66 \%$ of them had completed at least three online courses, and only $7 \%$ had not completed an online course. The students were otherwise characterized as under 30 years of age (86\%) and employed, either in a full-time or part-time position (69\%), with a GPA greater than $2.50(90 \%)$. More of the students who completed the survey attended school mostly full-time (87\%) as opposed to mostly part-time (13\%). Forty-eight percent of the respondents were women and 51\% were men.

\section{Mobile Device Use}


The study first sought to determine if students used mobile devices to access course material and to complete course assignments. Only 5\% disagreed with the statement: I use mobile devices to access course materials. There was more diversity in responses to the item: I use mobile devices to complete course assignments in that $19 \%$ disagreed, $12 \%$ were neutral and $69 \%$ agreed.

The devices that were commonly utilized by students, both mobile devices and non-mobile devices (desktops and laptops) were explored. Students were asked to rate how they used each of the four different devices (desktop computers, laptop computers, tablets and smartphones). They responded using a scale that ranged from nonacademic use only to academic use only; the center of the scale was equal academic and nonacademic use. They also had an option to report that they did not use the device. Results were tabulated and are presented in Table 2, followed by Figure 1.

Table 2: Device by Use

\begin{tabular}{l|rrrr}
\hline & \multicolumn{4}{|c}{ Type of Use } \\
Device & Academic & Equal & $\begin{array}{c}\text { Non } \\
\text { Academic }\end{array}$ & No Use \\
\hline Desktop & $36 \%$ & $36 \%$ & $14 \%$ & $13 \%$ \\
Laptop & $32 \%$ & $61 \%$ & $5 \%$ & $1 \%$ \\
I Pad / Tablet & $9 \%$ & $19 \%$ & $38 \%$ & $34 \%$ \\
Smart Phone & $4 \%$ & $24 \%$ & $71 \%$ & $1 \%$ \\
\hline
\end{tabular}

Note: NR data is not reported as less than $0.4 \%$ did not respond to a given item.

\section{Figure 1 Device by Use}

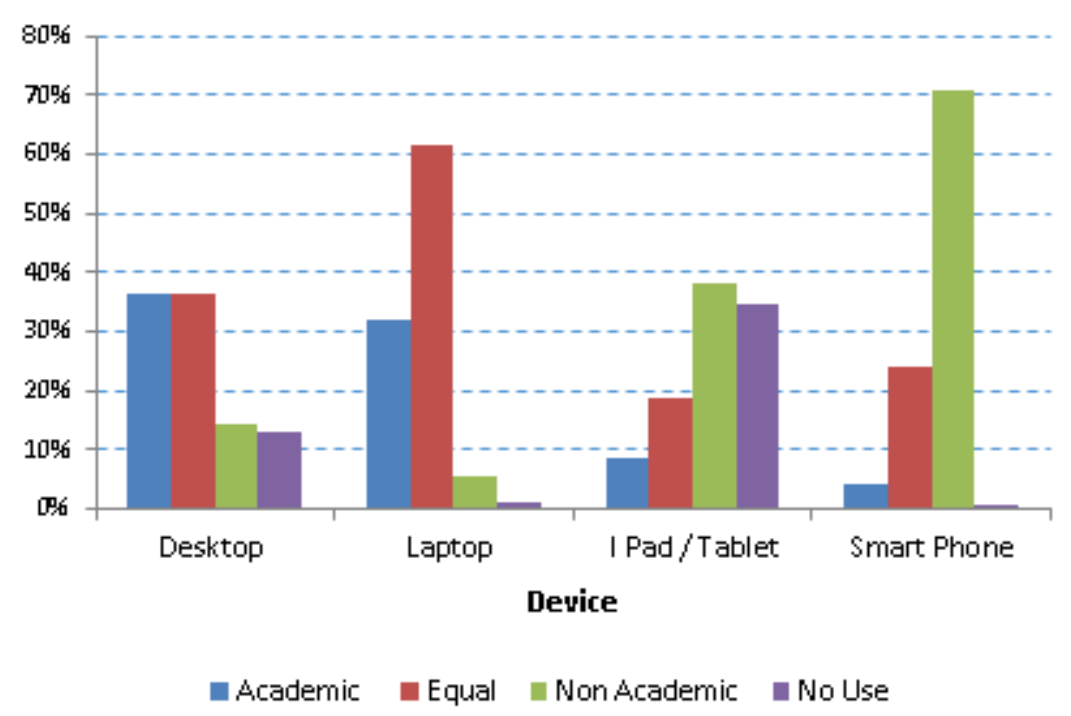

Indications were that students most frequently used desktops and/or laptops for their academic work, and they used smartphones for their nonacademic pursuits. The mobile device that was most frequently used for academic work was the laptop with about $93 \%$ reporting that they either 
used it exclusively for academic work or equally for academic and nonacademic efforts. Almost one-third $(28 \%)$ of the students used tablets for academic work only or for both academic and nonacademic work; slightly more than one-third (38\%) used tablets for only nonacademic work and another third did not use tablets. After the tablet being the device most categorized as not used, the desktop ranked next in that category, with $13 \%$ of the students having reported that they did not use the desktop at all. This result is notable for this study since it meant that $13 \%$ of respondents used only mobile devices or laptops. While laptops are not considered mobile ICTs since they are not handheld with touchscreens, they are most definitely portable devices, where desktops are not.

Analysis was completed to determine if age was related to the preferred device or if the number of online courses completed was related. In addition, the literature review revealed that most definitions of mobile learning encompass e-learning which is a synonym for online learning. Thus, it is interesting to examine whether a penchant for online learning implies something about the use of mobile devices. Results are summarized in Table3, Figure 2, Figure 3, and Table 4.

Table 3 Device Use by Age Category

\begin{tabular}{|l|r|r|r|r|r|r|r|r|}
\hline \multicolumn{1}{|c|}{ Age } & \multicolumn{4}{|c|}{$\leq \mathbf{2 6}$ yrs } & \multicolumn{4}{c|}{$\geq \mathbf{2 7}$ yrs } \\
\hline Use & Academic & Equal & Non academic & Not used & Academic & Equal & Non academic & Not used \\
\hline Desktop Computer & $40 \%$ & $31 \%$ & $14 \%$ & $14 \%$ & $25 \%$ & $50 \%$ & $16 \%$ & $9 \%$ \\
\hline Laptop Use & $32 \%$ & $59 \%$ & $7 \%$ & $1 \%$ & $30 \%$ & $66 \%$ & $2 \%$ & $2 \%$ \\
\hline I Pad or Tablet & $9 \%$ & $18 \%$ & $39 \%$ & $33 \%$ & $7 \%$ & $23 \%$ & $34 \%$ & $36 \%$ \\
\hline Smart Phone & $5 \%$ & $22 \%$ & $71 \%$ & $1 \%$ & $4 \%$ & $25 \%$ & $70 \%$ & $2 \%$ \\
\hline
\end{tabular}

Note: NR data is not reported as less than $0.4 \%$ did not respond to a given item.

\section{Figure 2 Device Use for Age $\leq 26$ Years}

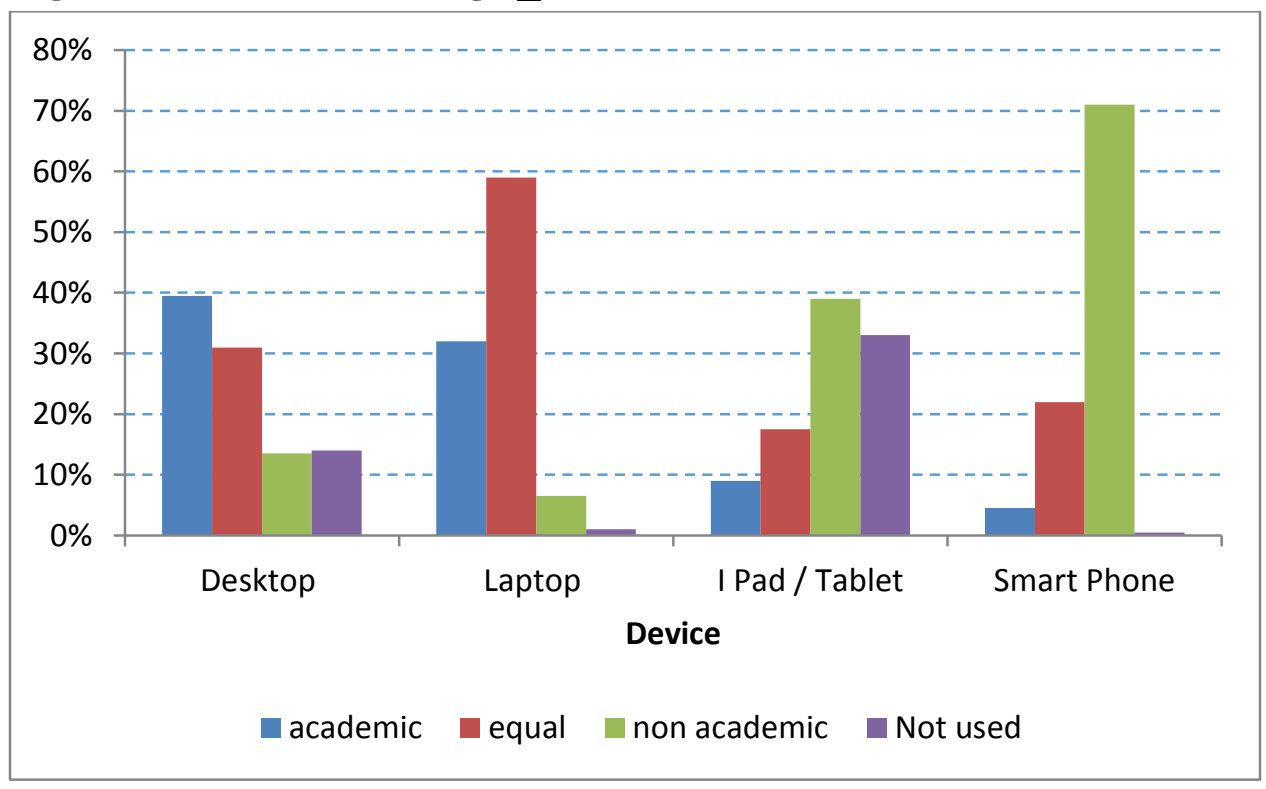


Figure 3 Device Use for Age $\geq 27$ Years

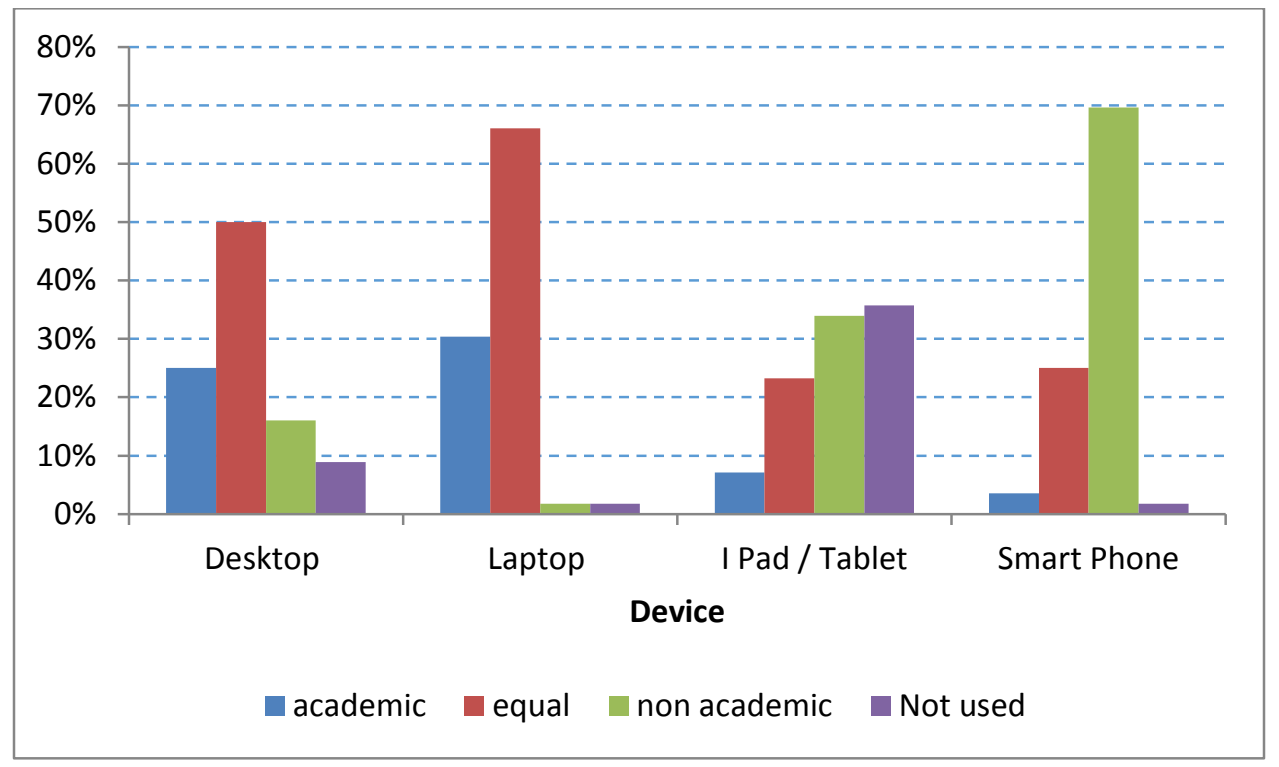

Forty percent of the students younger than 26 years of age used desktops only for academic work while $25 \%$ of the students at least 27 years of age used desktops only for academic work.

The impact of the number of online courses completed on the use of different devices is explored in Table 4 and Figure 3.1.

Table 4: Device Use by Number of Completed Online Courses

\begin{tabular}{|c|c|c|c|c|c|c|c|c|c|c|c|c|}
\hline & & & \multicolumn{9}{|c|}{ No. OL Courses } & \\
\hline & & \multicolumn{2}{|c|}{ One or Less } & \multirow[b]{2}{*}{ None } & \multirow[b]{2}{*}{ Acad } & \multicolumn{2}{|c|}{ Two or Three } & \multirow[b]{2}{*}{ None } & \multirow[b]{2}{*}{ Acad } & \multicolumn{2}{|c|}{ Four or More } & \multirow[b]{2}{*}{ None } \\
\hline & Acad & Equal & NonAcad & & & Equal & NonAcad & & & Equal & NonAcad & \\
\hline DT & $49 \%$ & $24 \%$ & $19 \%$ & $8 \%$ & $33 \%$ & $37 \%$ & $13 \%$ & $15 \%$ & $35 \%$ & $39 \%$ & $13 \%$ & $13 \%$ \\
\hline LT & $38 \%$ & $49 \%$ & $8 \%$ & $5 \%$ & $39 \%$ & $59 \%$ & $3 \%$ & $0 \%$ & $27 \%$ & $66 \%$ & $6 \%$ & $1 \%$ \\
\hline Tab & $5 \%$ & $22 \%$ & $27 \%$ & $46 \%$ & $12 \%$ & $19 \%$ & $24 \%$ & $45 \%$ & $8 \%$ & $18 \%$ & $49 \%$ & $26 \%$ \\
\hline SP & $3 \%$ & $24 \%$ & $73 \%$ & $0 \%$ & $4 \%$ & $28 \%$ & $67 \%$ & $0 \%$ & $5 \%$ & $22 \%$ & $72 \%$ & $1 \%$ \\
\hline
\end{tabular}

Note: NR data is not reported as less than $0.4 \%$ did not respond to a given item. 
Figure 3.1: Device Use by Number of Completed Online Courses

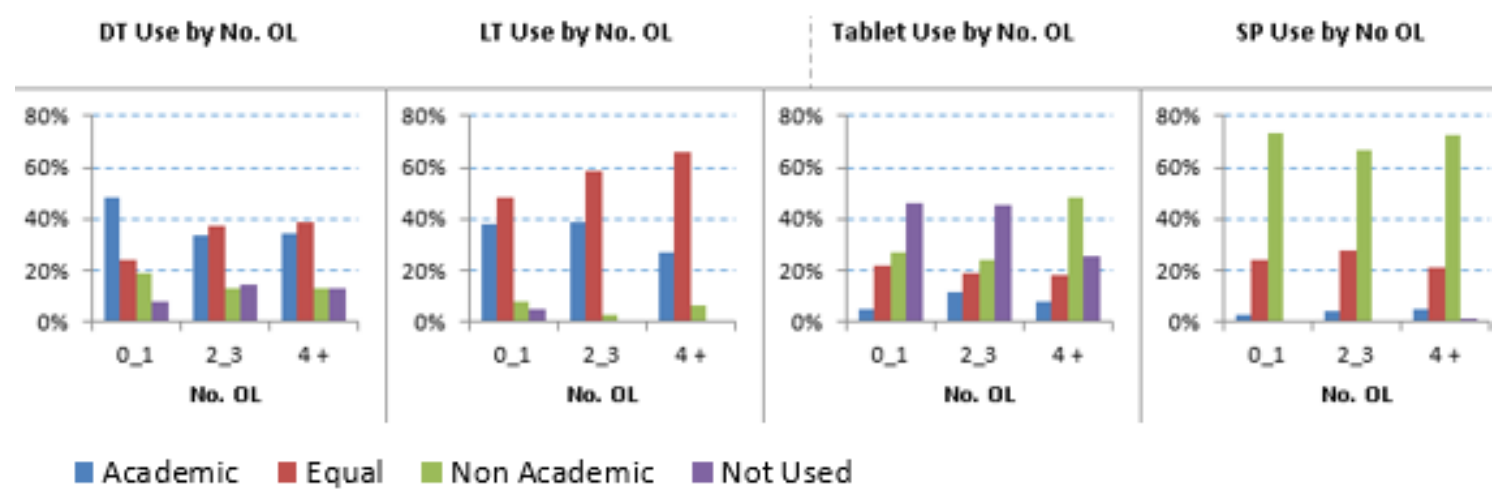

A desktop computer appeared as the device of choice or necessity for academic pursuits, particularly if the student has completed fewer than two online courses. In all cases, only $15 \%$ to $20 \%$ used the desktop exclusively for nonacademic pursuits and about 10\% to 15\% did not use it at all. Use of a desktop for academic work could be due to academic computer labs being provided on campus with the software necessary for various courses.

If a student completed two or more online courses, they were slightly more likely to use a laptop equally for academic and non-academic purposes than students with one or fewer online courses. This may demonstrate that as students gain experience with online courses, they also take advantage of the mobility such courses afford through the portability of laptops.

In general, tablets were less frequently used than desktops and laptops for academic work by these participants. About $25 \%$ to $30 \%$ of the students used tablets for at least some academic work. For students with three or fewer online courses, about a fourth of the students used them exclusively for nonacademic work, whereas if they had four or more online courses, about half used them only for nonacademic work, and another fourth of those students did not use tablets.

Smartphones were popular for nonacademic work. About a fourth of the students made some use of smartphones for academic work.

\section{Mobile Device Use for Lifelong Learning}

To explore the behaviors associated with lifelong learning with respect to mobile devices, students were asked to rate the extent to which they agreed that mobile devices enabled them to:

- actively participate in the learning process.

- learn from my peers.

- locate information from a wide variety of resources.

- integrate different ideas.

- use different learning strategies 
A semantic differential scale was used with a value of 7 meaning they strongly agreed and a value of 1 meaning they strongly disagreed. A mean was calculated and used to rank the behaviors. This ranking is shown in Table 5.

Table 5: Students Perceptions of Behaviors Related to the Use of Mobile Devices to Continue Learning

\begin{tabular}{|l|l|l|}
\hline Rank & Using mobile devices for learning enables me to: & Mean \\
\hline 1 & locate information from a wide variety of resources. & 5.99 \\
\hline 2 & integrate different ideas. & 5.48 \\
\hline 3 & use different learning strategies. & 5.44 \\
\hline 4 & participate actively in the learning process. & 5.38 \\
\hline 5 & learn from my peers. & 4.87 \\
\hline
\end{tabular}

In general, all activities students were polled about were enabled by mobile devices. Participants generally agreed that the identified behaviors were enabled by the use of mobile devices. The behavior that had the greatest association with being enabled by mobile devices was the location of information from a wide variety of sources. Although mobile devices were seen as helpful in learning from peers for lifelong learning, this association was smallest for these participants. The strength of association was about the same for the other three behaviors.

To further investigate if the behaviors enabled by mobile devices were associated with the number of completed online courses, contingency tables were constructed as presented in Table 6 and Figure 4 through Table 10 and Figure 8.

Table 6: Mobile Device Use for Information by No. OL

\begin{tabular}{|l|rrr|}
\hline No. OL & Disagree & Neutral & Agree \\
\hline$\leq 2$ & $11 \%$ & $29 \%$ & $60 \%$ \\
3 to 4 & $10 \%$ & $18 \%$ & $73 \%$ \\
$5+$ & $5 \%$ & $28 \%$ & $68 \%$ \\
\hline
\end{tabular}

Figure 4: Mobile Device Use for Information by No.

OL

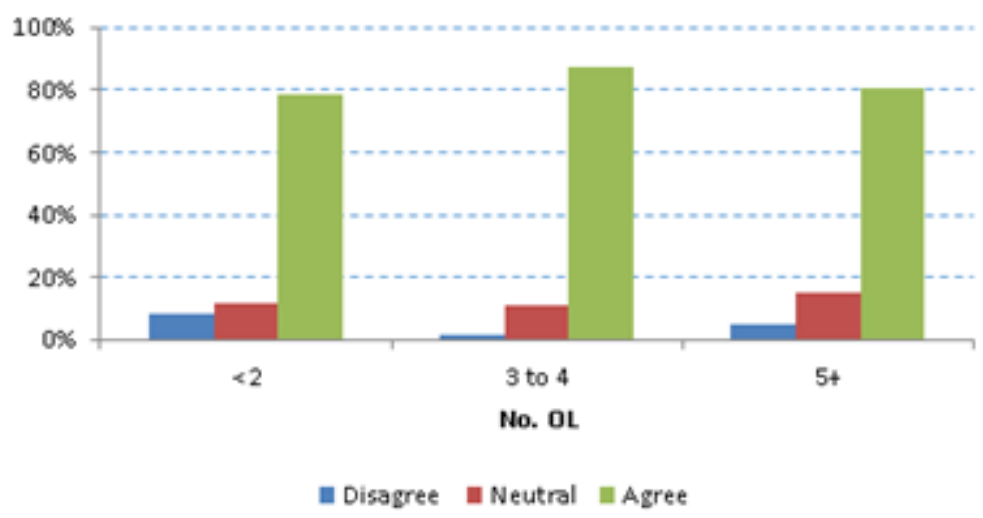


Table 7: Mobile Devices to Integrate Ideas by No. OL

\begin{tabular}{|l|rrr|}
\hline No. OL & Disagree & Neutral & Agree \\
\hline$\leq 2$ & $8 \%$ & $25 \%$ & $67 \%$ \\
3 to 4 & $0 \%$ & $19 \%$ & $81 \%$ \\
$5+$ & $7 \%$ & $15 \%$ & $78 \%$ \\
\hline
\end{tabular}

Table 8: Mobile Device Use for Strategies by No. OL

\begin{tabular}{|l|rrr|}
\hline No. OL & Disagree & Neutral & Agree \\
\hline$\leq 2$ & $12 \%$ & $26 \%$ & $61 \%$ \\
3 to 4 & $5 \%$ & $15 \%$ & $81 \%$ \\
$5+$ & $5 \%$ & $17 \%$ & $79 \%$ \\
\hline
\end{tabular}

Table 9: Mobile Devices for Learning Participation by No. OL

\begin{tabular}{|l|rrr|}
\hline No. OL & Disagree & Neutral & Agree \\
\hline$\leq 2$ & $11 \%$ & $29 \%$ & $60 \%$ \\
3 to 4 & $10 \%$ & $18 \%$ & $73 \%$ \\
$5+$ & $5 \%$ & $28 \%$ & $68 \%$ \\
\hline
\end{tabular}

Figure 5: Mobile Devices to Integrate Ideas by No. OL

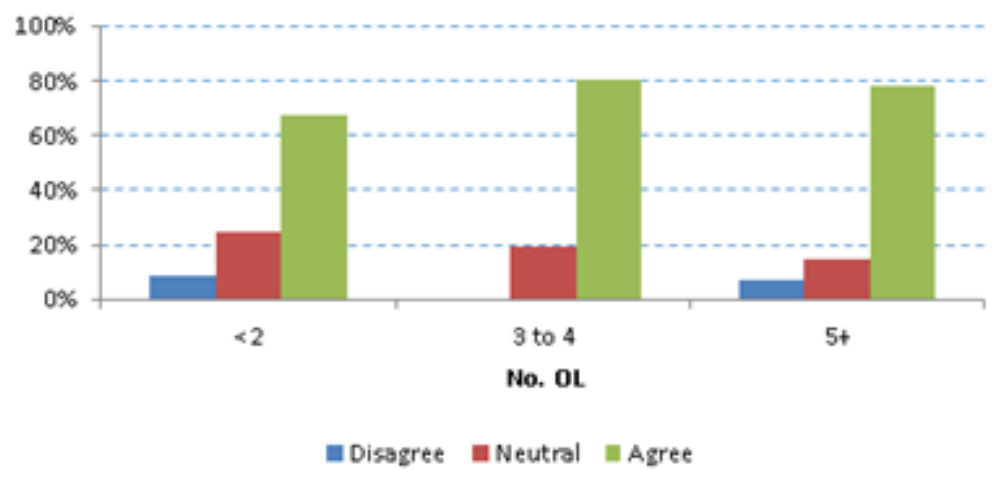

Figure 6: Mobile Device Use for Strategies by No. OL

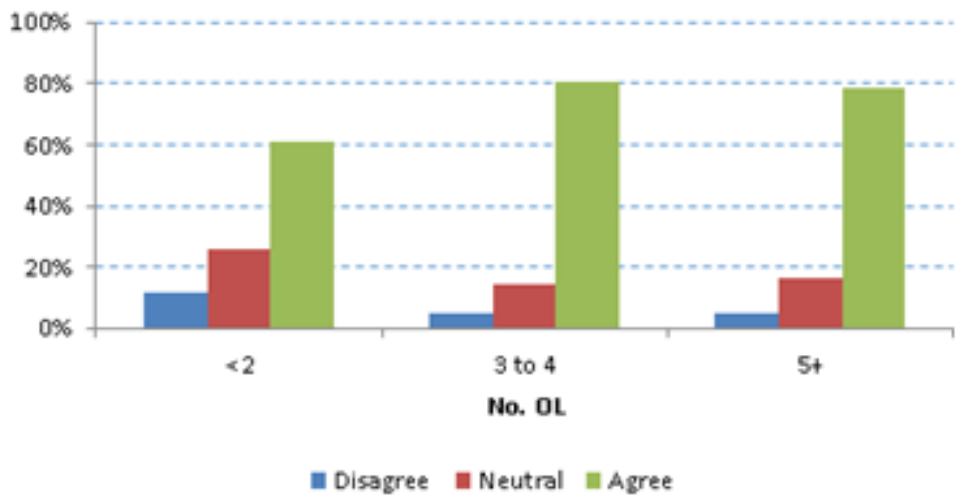

Figure 7: Mobile Devices for Learning Participation by No. OL

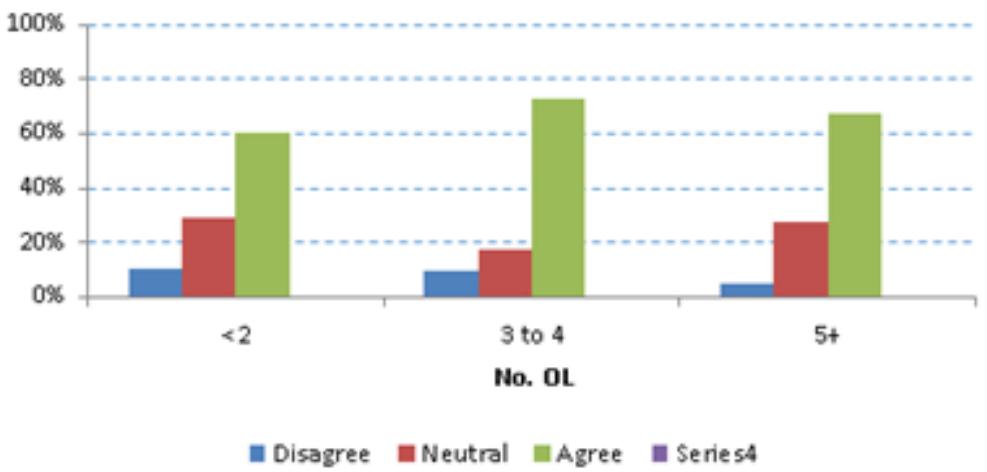


Table 10: Mobile Device Use for Peer Learning by No. OL

\begin{tabular}{|l|rrr|}
\hline No. OL & Disagree & Neutral & Agree \\
\hline$\leq 2$ & $15 \%$ & $39 \%$ & $46 \%$ \\
3 to 4 & $15 \%$ & $24 \%$ & $61 \%$ \\
$5+$ & $13 \%$ & $27 \%$ & $60 \%$ \\
\hline
\end{tabular}

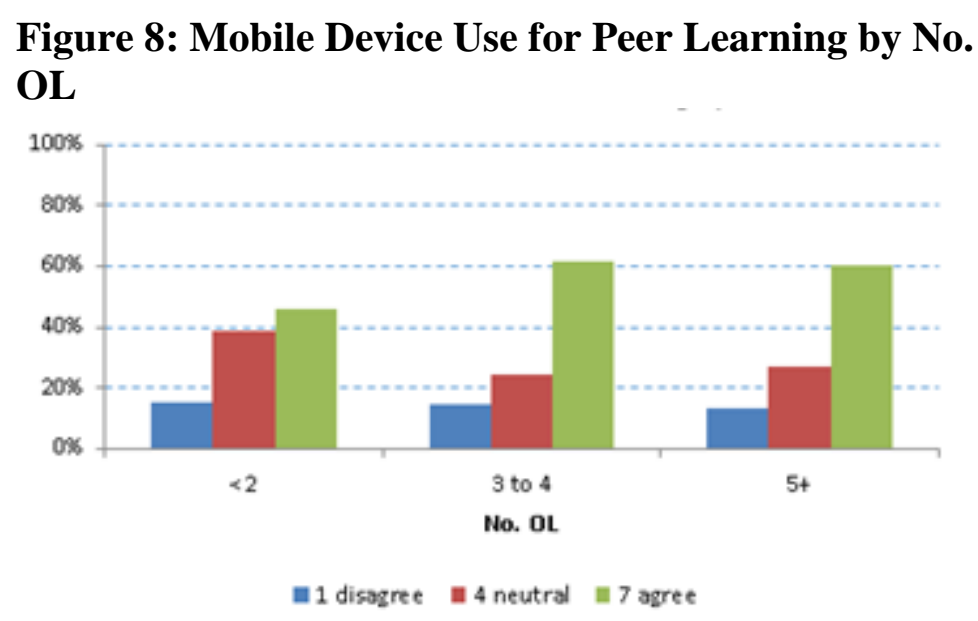

When the number of online courses exceeds 2 for the participants, they perceived greater benefit from the use of mobile devices. This association was strongest for compiling information, integration of ideas and the use of different learning strategies.

\section{Discussion and Conclusions}

In order to support educators who wish to help students learn to plan and accomplish goals within a lifelong framework of learning, the researchers recognized that it is desirable to understand how students perceive the lifelong learning process in the new world of readily accessible information along with learners who are mobile with a variety of devices that enable them to have anytime, anywhere access to learning environments. In particular, they were interested in exploring the ways students use mobile technologies for learning and how students perceive them to be useful for lifelong learning.

From the literature review, a number of related issues and challenges were identified.

\section{Mobile Learning}

Review of background research exposed several issues and challenges related to mobile learning and the use of technology, including technology devices, for lifelong learning. First, Sharples identified the lack of a ready-made theory of personal learning to use to inform design of technology to support learning in multiple contexts over long periods of time. ${ }^{8}$ Milrad raised questions concerning how learning activities using mobile technologies can be designed to support innovative education practices. ${ }^{22}$ Sharples also wrote on this theme by questioning how the use of mobile devices can be integrated within broader educational scenarios. ${ }^{23}$ Taylor expressed concerns for a lack of development of appropriate methods for evaluating learning in mobile environments. ${ }^{18}$ Tension between informal networked learning interactions and school education regulated by a set curriculum provides further challenges. Sharples wrote that most schools and colleges do not recognize informal networked interaction as legitimate learning and even forbid students to bring phones and personal computers into the classroom. ${ }^{23}$ 


\section{Technology/Devices}

Issues and challenges related to technology and technology devices for lifelong learning appeared in two primary areas: the attributes of devices and personal characteristics of the learner. Sharples proposed that challenges related to attributes of devices can be mitigated by devices that are highly portable, individual, unobtrusive, available, adaptable, persistent, useful, and intuitive. ${ }^{8}$ The second issue related to the level of self-organization presents greater challenge because capacities for self-organization and self-directedness are characteristics inherent within the learner. Questions of how to use technology to develop these characteristics in learners merits further exploration.

\section{Lifelong Learning}

While lifelong learning offers the opportunity to invest in human capital, to raise educational levels, and allow sustainable development of citizens, challenges also exist. ${ }^{9}$ Kalz identified a need to dismantle barriers for lifelong learning and encouraged society as a whole to engage in supportive research and development activities. ${ }^{21}$ Identified barriers included a poor family culture of learning, lack of financial resources, providers not geared to the needs of learners, poor information services to attract learners, distance, facilities, and misconceptions of the benefits of lifelong learning. Bosco stated, "Opportunities for lifelong learning are great and growing quickly. ... Prevalence and potency of these resources will continue to expand.... We can be assured that those who are developing hardware and applications will continue to make progress. The extent to which these new resources will yield the benefits which are needed will be determined by our ability to meet several challenges". ${ }^{2}$ The challenges listed by Bosco include access to technology; disposition or desire, including the ability to cultivate rather than exterminate interests; and capability, where each person becomes their own teacher. To summarize, Bosco stated, "The disposition of wanting to learn must be matched by the capability to be able to do so". 2

\section{Study Results}

This study was designed to examine how students use mobile devices to support their learning and what students perceive as the relationship between mobile devices and lifelong learning by asking three questions. a) What devices are commonly utilized by students to support learning? b) How much do students use mobile devices for learning, especially compared to their use of laptops and desktops? And c) how do students perceive that they can use mobile devices to continue learning? The results indicate that students generally do use mobile devices to complete coursework. The device most frequently used was a portable but not hand-held device, the laptop (93\%). Laptop use was followed by mobile devices which included tablets and smartphones (each 28\%). Interesting among these results is the finding that 13 percent of students use only mobile or portable ICT devices for academic work. For educators, the concept that not only do a majority of students use mobile ICT devices to support their learning, but also that some students use only mobile or portable ICT devices merits consideration related to both curriculum design and delivery. It is possible students use portable but not mobile devices, not due to the limitations of the devices or to their own needs for mobility, but due to the limitations of the instruction 
modes employed in curricula and courses. This concept merits further research with an eye toward what instructional design characteristics support mobility in learning.

Two-thirds of the students expressed that mobile devices helped with lifelong learning. They shared that using mobile devices for learning enables them to locate information from a wide variety of resources (rank 1), integrate different ideas (rank 2), use different learning strategies (rank 3), participate actively in the learning process (rank 4), and learn from peers (rank 5). Students' substantial use of mobile devices to locate information from a wide variety of resources is reflective not only of their awareness of the ever-increasing amount of information available to them, but also of their desire and need to use available tools to enable them to access and apply it.

For educators seeking to prepare students for ever-expanding and evolving bodies of knowledge, these findings offer a positive forecast for future learning environments in that students reported using mobile tools to engage with critical resources. This process is likely to accelerate as indicated by the finding that as the number of online courses students had taken increased, they perceived greater benefit from the use of mobile devices. The findings suggest that they were learning through experience to use available tools to facilitate learning anytime and anywhere. Further study and research is needed to help educators understand how to structure content and interaction for mobility, and thus, to model for students ways to continue to learn outside of a structured course or curriculum. Additional areas for investigation may include considerations of age as a variable in the use of devices for lifelong learning and correlations between device usage and student outcomes.

In summary, advanced technical tools now facilitate the ability of students to learn anytime, anywhere. Students use mobile devices for learning and view them as positive tools for lifelong learning. This result has substantial implications not only for lifelong learning for individuals, but also for curriculum design and application geared to enhance and facilitate the learning process throughout the lifecycle.

\section{Bibliography}

1. Toffler, A. (2016). Alvin + Heidi Tofler - Futurists Retrieved Jan 28, 2016, from http://www.alvintoffler.net/?fa=galleryquotes.

2. Bosco, J. (2007). Lifelong Learning: What? Why? How? Western Michigan University. Kalamazoo, MI.

3. ABET. (2016). Criteria for Accrediting Engineering Programs, 2016-2017: Accreditation Board for Engineering and Technology.

4. ABET. (2016). Criteria for Accrediting Applied Science Programs, 2016-2017: Accreditation Board for Engineering and Technology Programs.

5. ABET. (2016). Criteria for Accrediting Engineering Technology Programs, 2016-201: Accreditation Board for Accrediting Engineering and Technology.

6. ABET. (2016). Criteria for Accrediting Computing Programs, 2016-2017: Accreditation Board for Engineering and Technology Programs.

7. Sharples, M. (2000). The design of personal mobile technologies for lifelong learning. Computers \& Education, 34(3-4), 177-193. doi: http://dx.doi.org/10.1016/S0360-1315(99)00044-5

8. Sharples, M. (2002). Disruptive devices: Mobile technology for conversational learning. International Journal of Engineering Education and Life-long Learning, 12(5/6), 504-520. 
9. Ion, A., \& Bentley, M. (2015). Mobile Technologies for Lifelong Learning. Informatica Economica, 19(2).

10. Henschke, J. A. (2014). An International Perspective on Reorienting Traditional Higher Education Institutions toward Lifelong Learning. Procedia - Social and Behavioral Sciences, 142, 36-46. doi: http://dx.doi.org/10.1016/j.sbspro.2014.07.585.

11. Bentley, T. (1998). Learning Beyond the Classroom. London, GBR: Routledge.

12. Nordin, N., Embi, M. A., \& Yunus, M. M. (2010). Mobile Learning Framework for Lifelong Learning. Procedia - Social and Behavioral Sciences, 7, 130-138. doi: http://dx.doi.org/10.1016/j.sbspro.2010.10.019.

13. Laal, M. (2013). Key Necessities for Lifelong Learning. Procedia - Social and Behavioral Sciences, 83, 937 941. doi: http://dx.doi.org/10.1016/j.sbspro.2013.06.175.

14. Idrus, R. M., \& Atan, H. (2007). Lifelong and lifewide distance education. In A. R. Norizan (Ed.), Online Lifelong Learning in Malaysia: Research and Practice (pp. 30-41): UPM Press.

15. Hargreaves, A. (2003). Teaching in the Knowledge Society: Education in the Age of Insecurity. New York, NY: Teachers College Press.

16. Sharples, M., Taylor, J., \& Vavoula, G. (2005). Towards a theory of mobile learning. Paper presented at the mLearn 2005: 4th World Conference on mLearning, Capetown, South Africa.

17. Winters, N. (2006). What is mobile learning? In M. Sharples (Ed.), Big Issues in Mobile Learning (pp. 4-8). Nottingham, UK: Kaleidoscope Network of Excellence.

18. Taylor, J. (2006). Evaluating mobile learning: What are appropriate methods for evaluating learning in mobile environments? In M. Sharples (Ed.), Big Issues in Mobile Learning (pp. 24-26). Nottingham, UK: Kaleidoscope Network of Excellence.

19. Walker, K. (2006). Introduction: Mapping the Landscape of Mobile Learning. In M. Sharples (Ed.), Big Issues in Mobile Learning (pp. 2-3). Nottingham, UK: Kaleidoscope Network of Excellence.

20. Jones, A., Issroff, K., Scanlon, E., McAndrew, P., \& Clough, G. (2006). Affective factors in learning with mobile devices. In M. Sharples (Ed.), Big Issues in Mobile Learning (pp. 15-20). Nottingham, UK: Kaleidoscope Network of Excellence.

21. Kalz, M. (2015). Lifelong Learning and Its Support with New Technologies A2 - Wright, James D International Encyclopedia of the Social \& Behavioral Sciences (Second Edition) (pp. 93-99). Oxford: Elsevier.

22. Milrad, M. (2006). How should learning activities using mobile technologies be designed to support innovative edcuational practices? In M. Sharples (Ed.), Big Issues in Mobile Learning (pp. 27-29). Nottingham, UK: Kaleidoscope Network of Excellence.

23. Sharples, M. (2006). How can we address the conflicts between personal informal learning and traditional classroom education? In M. Sharples (Ed.), Big Issues in Mobile Learning (pp. 15-20). Nottingham, UK: Kaleidoscope Network of Excellence. 